\title{
Analyzing the Application of Void Decks on High-rise Affordable Housing in Jakarta, Indonesia, to Achieve Optimal Urban Ventilation
}

\author{
Megan Afkasiga Ririhena ${ }^{1, *}$ and Nedyomukti Imam Syafii ${ }^{1}$ \\ ${ }^{1}$ Department of Architecture and Planning, Universitas Gadjah Mada, Jl. Grafika No. 2, Yogyakarta 55281, Indonesia \\ *Corresponding author: meganafkasiga@mail.ugm.ac.id
}

\author{
KEYWORDS \\ Rusun \\ Urban ventilation \\ Wind flow \\ Wind speed
}

SUBMITTED 6 June 2021

REVISED 18 November 2021

ACCEPTED 29 November 2021

\begin{abstract}
Economic growth in ASEAN countries encourages significant urbanized growth. In line with the growth of urbanization, large swathes of residential buildings have been constructed in urban areas, especially, in the case of Indonesia, through the government's 1000 rusun (high-rise affordable housing) development program in Jakarta. In order to reduce energy consumption and create a sustainable rusun, a passive strategy is needed in the form of natural air conditioning through optimized natural ventilation in these buildings. In this study, testing was conducted on Rusun Rorotan in Jakarta, from two wind source directions (north and northwest) with five void decks configuration samples each, in order to determine wind flow and wind speed patterns in the Rusun area. For this purpose, the wind tunnel simulation method using the Butterfly plugin in Grasshopper was employed. These results should provide a reference for future residential property developers, especially in the scope of other countries in ASEAN, which have similar climatic conditions to that of Indonesia.
\end{abstract}

(๑) The Author(s) 2022. This article is distributed under a Creative Commons Attribution-ShareAlike 4.0 International license.

\section{INTRODUCTION}

It is estimated that by the end of this century, $50 \%$ of the world's population will live in urban areas and about $20 \%$ of them will consume $80 \%$ of the available energy mostly through the use of artificial air conditioning (Sugini 2014). Countries in ASEAN have experienced economic growth that has had an impact on rapid urbanization growth in recent years, increasing urban energy consumption, with the use of air conditioners having the highest percentage, at 56\% (Katili et al. 2015). As a result, residential areas inhabited by low-income people tend to be dense and do not pay attention to existing settlement standards, ultimately creating other slums. The Government of Indonesia has aimed to address this problem through the 1000 rusun tower program (Vialita and Rahmawati 2020).

In the development of rusun in Indonesia, a sustainable development strategy is needed with passive design methods. Based on the statistics above, air conditioning is one of the issues that are highlighted in energy use. Natural ventilation can offer healthy and comfortable ventilation without the need for additional energy, but to design natural ventilation, supportive conditions are required, such as healthy outdoor air, mild outdoor air temperature, and not many surrounding buildings that block air flow (Satwiko 2004). In its application, wind is an important environmental parameter concerning temperature and radiation. In dense urban areas with high-rise buildings, the wind speed that reaches the middle of the city becomes small ( $\mathrm{Ng} 2009)$. The condition of a high-density city filled with high-rise buildings will be much more effective in forming air routes through the gaps between buildings (Givoni 1998). Based on this, a sustainable development strategy with one of the urban ventilation strategies is required. One of them is the use of void decks (VD) that are expected to optimize natural ventilation in the circulation and distribution of wind flow in the rusun area scale to reduce the use of energy in artificial air conditioning in the high-rise rusun buildings.

Rusun or high-rise affordable housing is a type of housing with limited price segments or rents that are provided by the government to low-income households, to balance investment, building rusun must have high economic efficiency (Adabre et al. 2020). Rusun has some flexibility limitations for its users, one of which is in conditioning the conditioning of each unit, where residents are not allowed to install air conditioning on the unit.

To realize strong sustainability, it is important to emphasize environmental aspects. DeKay and Brown (2014) classifies green design techniques capable of being applied in the schematic design stage according to his technique of complexity and scale divided into group scales of buildings, building scales, and building parts (Lee et al. 2015). The environmental control area of passive design techniques includes light environment, air environment, and thermal environment. Referring to the Koppen-Geiger world climate classification, Indonesia has a tropical climate with high humidity or so-called humid tropical climate (Peel et al. 2007). Dry seasons and rains can last a long time and often overlap between the two seasons.

One of the passive design techniques for controlling air in space stems from the consideration of improving the effectiveness of natural ventilation. Furthermore, wind speeds of approximately $1 \mathrm{~m} / \mathrm{s}$ are required for indoor temperatures, $1.5 \mathrm{~m} / \mathrm{s}$ for outdoor temperatures, and $5 \mathrm{~m} / \mathrm{s}$ on foot to achieve thermal comfort (Keung 2010). 
Urban ventilation is an important principle that plays a role in whether or not to achieve natural ventilation in the space of buildings, the spread of pollution, and thermal comfort in urban areas. At an altitude of $500 \mathrm{~m}$ which is the peak of the boundary layer wind speed of $100 \%$ and is not affected by the surface conditions of the Earth (Satwiko 2004). The wind velocity ratio (VRw) is a ratio of winds from $2 \mathrm{~m}$ to $500 \mathrm{~m}$ above the ground level indicating how much wind reaches an urban area (Ng 2009). Urban canyon ratios affect turbulence or circulation of air vortexes (AV) between buildings as reviewed from the comparison of building height and distance between buildings ( $\mathrm{Ng}$ 2009). The higher the ratio of building height to distance between buildings, the smaller av circulation on the surface. The proximity between buildings triggers stagnant airflow where buildings do not get sufficient wind distribution because they are blocked by nearby buildings. VD is an open area on the ground floor of a housing estate that has been first developed by the Housing Development Board (HDB) in Singapore, VD is a development rule of HDB that is accessible to residential residents (Cairns et al. 2014). The VD was not integrated with HDB blocks at the time of its inception but was introduced in the 1970s for 10 years after the construction of the initial housing model.

This study aimed to create an example of a passive design strategy with the application of urban ventilation with void decks. Method and its influence on natural ventilation to reduce energy use by improving wind flow circulation so that it can distribute wind to each unit in the rusun area. The research sample was taken from an area of high-rise affordable housing area located in Jakarta in Indonesia to represent an urban situation with a humid tropical climate that is also owned by other ASEAN countries. Rusun Rorotan became a research sample because it has a form of slab blocks with four layers of tower buildings that have optimal geometry in testing wind direction. Wind conditions in the northern Jakarta area close to the sea have strong wind conditions from the north, especially in the morning to noon. Wind conditions at the rusun location are described below.

The results of this study are expected to contribute to the advancement of settlement infrastructure. Especially high-rise settlements in the ASEAN region in optimizing the use of natural ventilation with the method of applying VD. In this way, the optimal use of natural ventilation can reduce the use of artificial air conditioning in tackling energy issues in ASEAN.

\section{MATERIALS AND METHODS}

\subsection{Simulation method}

Computational fluid dynamics (CFD), a method of software analysis, was used in this study. CFD simulation is an alternative method to accurately predict wind movement that allows the design to be more effective and can be

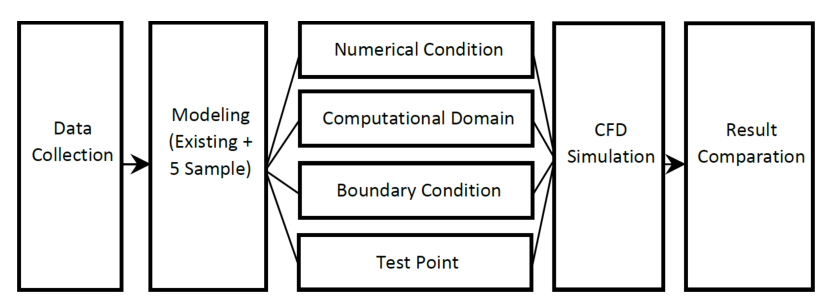

FIGURE 1. Diagram of analysis process. learned before the design resumes at a later stage (Keung 2010). There are three stages in CFD simulation, in general, namely pre-processing, solving, and post-processing (Keung 2010). The software used to run CFD was Butterfly, which is one of the simulation tools of Ladybug Tools. Rusun area modeling used Rhinoceros and was simulated with Grasshopper to simulate CFD using Butterfly. Butterfly itself uses OpenFOAM as a device that can run CFD simulations with the tightest validation and run several advanced simulations and turbulence models, including simple RAS and intensive tutoring.

\subsection{Data collection}

Data collection was done secondary from Google Earth software in the study of mass geometry and distance between buildings. Simulation used a 1:1 scale with the Rhinoceros modeling software. The modeling simulated in this study referred to previous research by $\mathrm{Ng}$ (2009) on urban canyons with a composition of $\mathrm{W}: \mathrm{H}=1: 2$, with mass geometry of slab blocks.

The height of the rusun towers was $51.2 \mathrm{~m}$, with the distance between the towers being $25 \mathrm{~m}$ (Figure 2). Comparison of tower height and distance between towers following the composition of urban canyons $\mathrm{W}: \mathrm{H}=1: 2 \mathrm{ac}-$ cording to previous research. The VD configuration in this study focused on the position of VD at several heights, each VD height as a representation of the height average of the tower, the ground floor of the building (ground floor), medium (8th floor), and top (15th floor) of a total of 16 floors of the building. The VD position on the ground floor of the existing tower was maintained (0: ground floor) by adding VD positions on the middle floor of the tower (A: 8th floor) and the top of the tower (B: 12th floor) with a total of five scenarios (S) with one VD position in each tower of a total of four towers.

For numerical conditions, this research attempted to solve one of the Reynold-Average Simulation (RAS) turbulence equations using OpenFOAM, which is commonly referred to as Reynolds-Averaged Navier-Stokes (RANS). The RAS equation measures each turbulence and completes each movement's average record. Because this study used the wind tunnel (WT) method, RAS equations were most adequate in the representation of wind tunnel reality because of the approach of average time conditions in WT that do not change (Franke 2007).

The computational domain focused on the coefficient of numbers on WT, terrain, and boundary mesh geometry to be simulated. Volume composition WT was based on

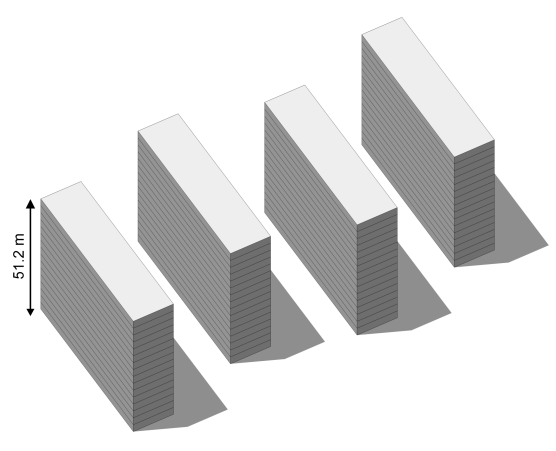

(a)

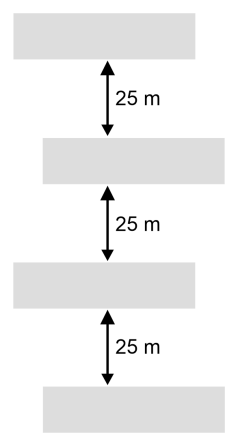

(b)
FIGURE 2. (a) Interpretation of axonometry modeling of Rusun Rorotan, Jakarta, in Rhinoceros, and (b) site plan and site orientation. 
the height $(\mathrm{H})$ of the tower $(51.2 \mathrm{~m})$ with the optimal composition of OpenFOAM namely windward $3 \mathrm{H}$, leeward $15 \mathrm{H}$, width left-right building $5 \mathrm{H}$, and height $5 \mathrm{H}$ from the site area (Figure 3). The terrain condition on WT is 0 or without obstacles surrounding buildings because the research will focus on $\mathrm{V}$ inside the area between the towers inside the site.

\subsection{Modeling}

The computational grid used a staggered grid model where the density was adjusted to the position of the building model and adjusted to OpenFOAM settings to determine how much turbulence was received on each building mass (Figure 4). The closer to the mass of the building, the tighter the grid on the meshing, which consequently indicates the greater the turbulence created by the closer WF and the mass of the building.

Boundary conditions in this study used wind speed (V) data from a wind rose of Jakarta with an annual average in 2020 (Figure 5). The V value used in the study takes from the direction that had the highest $\mathrm{V}$ value. The value of $\mathrm{V}$ with different wind directions was simulated as a comparison and limitation of the research. Based on WR data, the $\mathrm{N}$ (north) wind had the largest average wind speed with a $\mathrm{V}$ value of $3.11 \mathrm{~m} / \mathrm{s}$ and the V value in the WT simulation with a straight wind direction towards the building. For comparison, the simulation was conducted with winds from the NW (northwest) direction with an average value of V $2.68 \mathrm{~m} / \mathrm{s}$

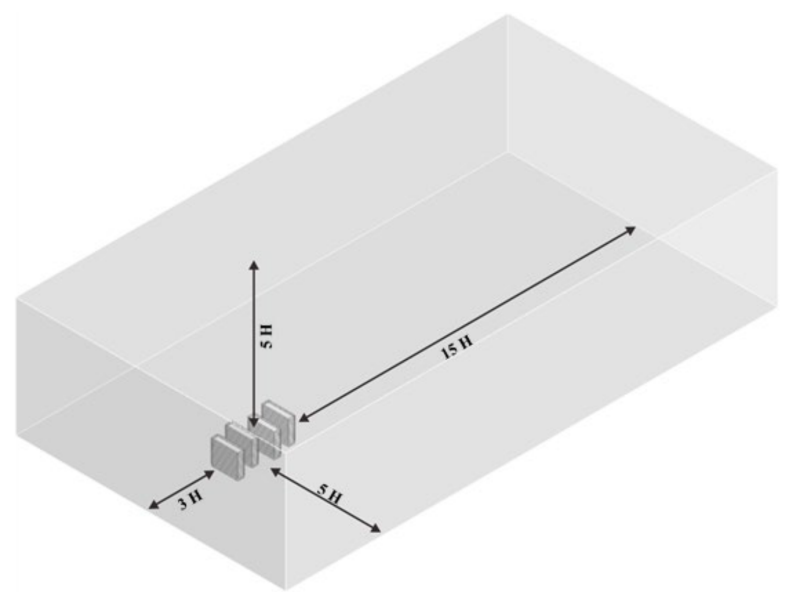

FIGURE 3. 3D wind tunnel configuration.

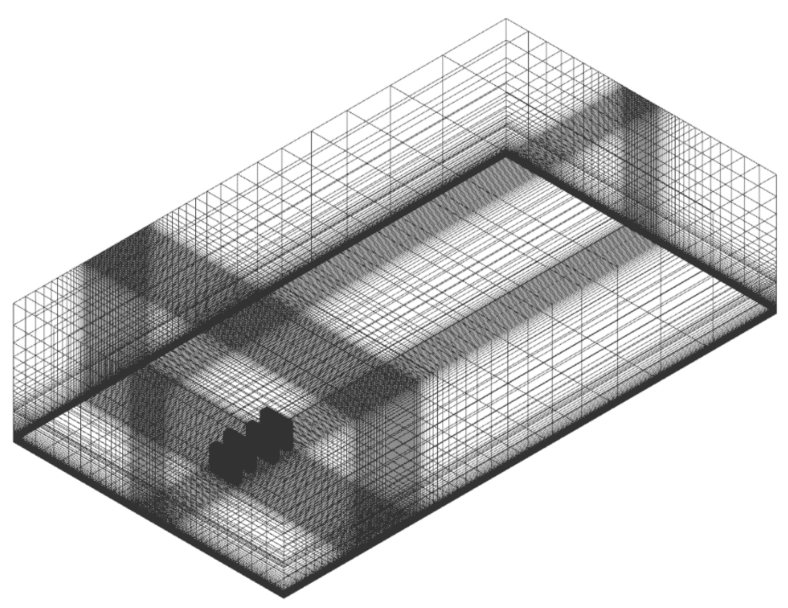

FIGURE 4. Boundary mesh. with a diagonal wind direction. Both directions of the wind source focused on testing the permeability of the building in the distribution of wind that passes through the tower 1 building to the next tower building. The value of the second $\mathrm{V}$ of the direction of the wind exceeds the recommended wind speed ratio requirement according to the literature.

The analysis focused on the $\mathrm{V}$ values on the 5 th, 10th, and 15th floors of the area's symmetrical line area focusing on the area between each tower building. The test point was divided into three areas and three heights located on the 5 th floor with a height of $14.4 \mathrm{~m}$ as the height of the middle to the bottom, on the 10th floor with a height of $30.4 \mathrm{~m}$ as the middle height, and on the 15th floor with a height of $40.4 \mathrm{~m}$ as the height of the middle to the top. Points a, $\mathrm{c}$ and $\mathrm{e}$ are on the south of each tower building as the leeward wall, and points $b, d$, and $f$ are on the north wall of each tower building as the windward wall. The test point simulates vertically on a line of symmetry to determine the sample and represent the outline of the outdoor wind speed (V) conditions in the rusun area.

\section{RESULTS}

CFD analysis in two wind direction scenarios namely wind from the north with a speed of $3.11 \mathrm{~m} / \mathrm{s}$ and wind from the northwest at a speed of $2.68 \mathrm{~m} / \mathrm{s}$ with wind tunnel simulation method at each existing modeling and five samples with different VD configurations to find the pattern and tendency of WF (Wind Flow) and V (Wind Speed) at each test point (Figure 6) to obtain an optimal VD configuration when reviewed from the sample rusun.

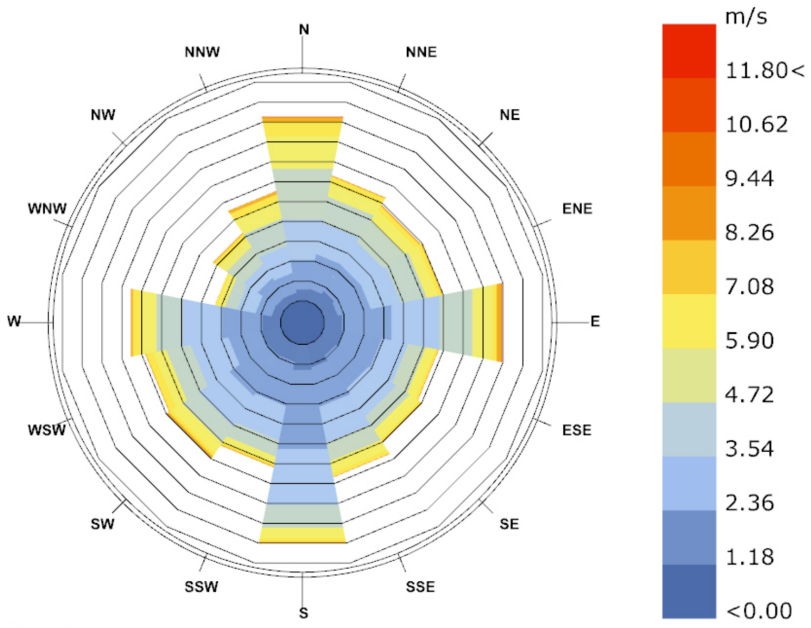

Wind-Rose

Jakarta Kemayoran_JW_IDN

1 JAN 1:00 - 31 DEC 24:00

Hourly Data: Wind Speed $(\mathrm{m} / \mathrm{s}$ )

FIGURE 5. Wind rose of Jakarta generated with Grasshopper.

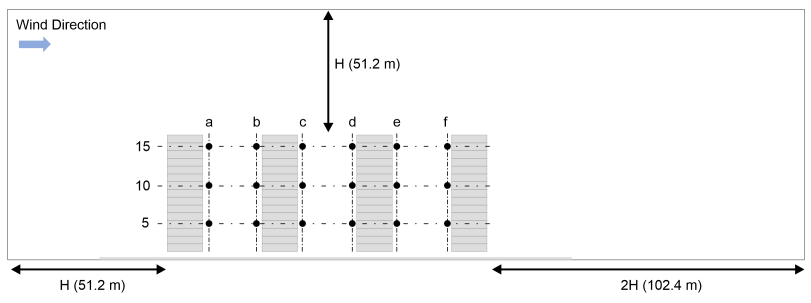

FIGURE 6. Elevation view of simulation test point. 


\subsection{North wind}

In the north wind simulations with a V speed of $3.11 \mathrm{~m} / \mathrm{s}$, the lowest WF was found to be located at the point of the south wall (a, c, e) between the 5th, 10th, and 15th floors in each area, with an average $\mathrm{V}$ of $0.25 \mathrm{~m} / \mathrm{s}$ (Table 1). Meanwhile, the highest WF tended to be at the north wall point (b, d, f) on the 10th floor in areas 2 and 3 with an average $\mathrm{V}$ of $2.51 \mathrm{~m} / \mathrm{s}$. Turbulence was located on the high floor area (floors 13-15) and low level (floors 1-5) in area 1 located between tower 1 and tower 2 in sample 1 to sample 5 . WF was quite large in the VD 1st floor (0) and 8th floor (A) in tower 1 and tended to decrease in the next tower until the last tower, whereas sample $1(\mathrm{~A}-\mathrm{A}-\mathrm{A}-\mathrm{A})$ showed a somewhat different result, where the WF tended to increase only in the last tower (tower 4). The difference in the average value of $\mathrm{V}$ was quite significant from the existing simulation with the five sample simulations, with a difference of $1.08 \mathrm{~m} / \mathrm{s}$ between the existing configuration and $\mathrm{S} 2$ as the lowest average sample. However, the average difference in $\mathrm{V}$ values from each sample was not very significant, at $1.28 \mathrm{~m} / \mathrm{s}<\mathrm{V}$ $<1.40 \mathrm{~m} / \mathrm{s}$. From the difference in the average value of $\mathrm{V}$ in the north wind above, indications are that the addition of VD other than the ground floor contributes a significant influence to WF in the rusun area when the wind direction comes straight on, especially from the north, as reflected in this simulation.

Based on the leeward and windward trendlines of the north wind (Figure 7), the five samples of VD configuration in the rusun area had an average pattern of $\mathrm{V}$ value in windward which tended to be the same which was increased from wall $\mathrm{b}$ to highest on wall $\mathrm{f}$. Meanwhile, on the leeward wall there was a decreases pattern of the $\mathrm{V}$ value from wall a to wall $\mathrm{c}$ and returns slightly increased on wall $\mathrm{f}$. In the direction of the perpendicular wind, the VD configuration in the first tower building does not affect the distribution of wind significantly in subsequent tower buildings when viewed from the sample pattern of S3 and S4 cases. The difference in the average value of $\mathrm{V}$ was quite significant from the existing simulation with the five sample simulations with a difference of $1.08 \mathrm{~m} / \mathrm{s}$ between existing and $\mathrm{S} 2$ as the lowest average sample. However, the average difference in $\mathrm{V}$ values from each sample was not very significant which was $1.28 \mathrm{~m} / \mathrm{s}<\mathrm{V}<1.40 \mathrm{~m} / \mathrm{s}$. From the difference in the average value of $\mathrm{V}$ north wind above it can be known that the addition of VD other than the ground floor gives a significant influence on WF in the Rusun area when the wind direction comes straight, especially from the north in this simulation.

TABLE 1. North wind simulation results.

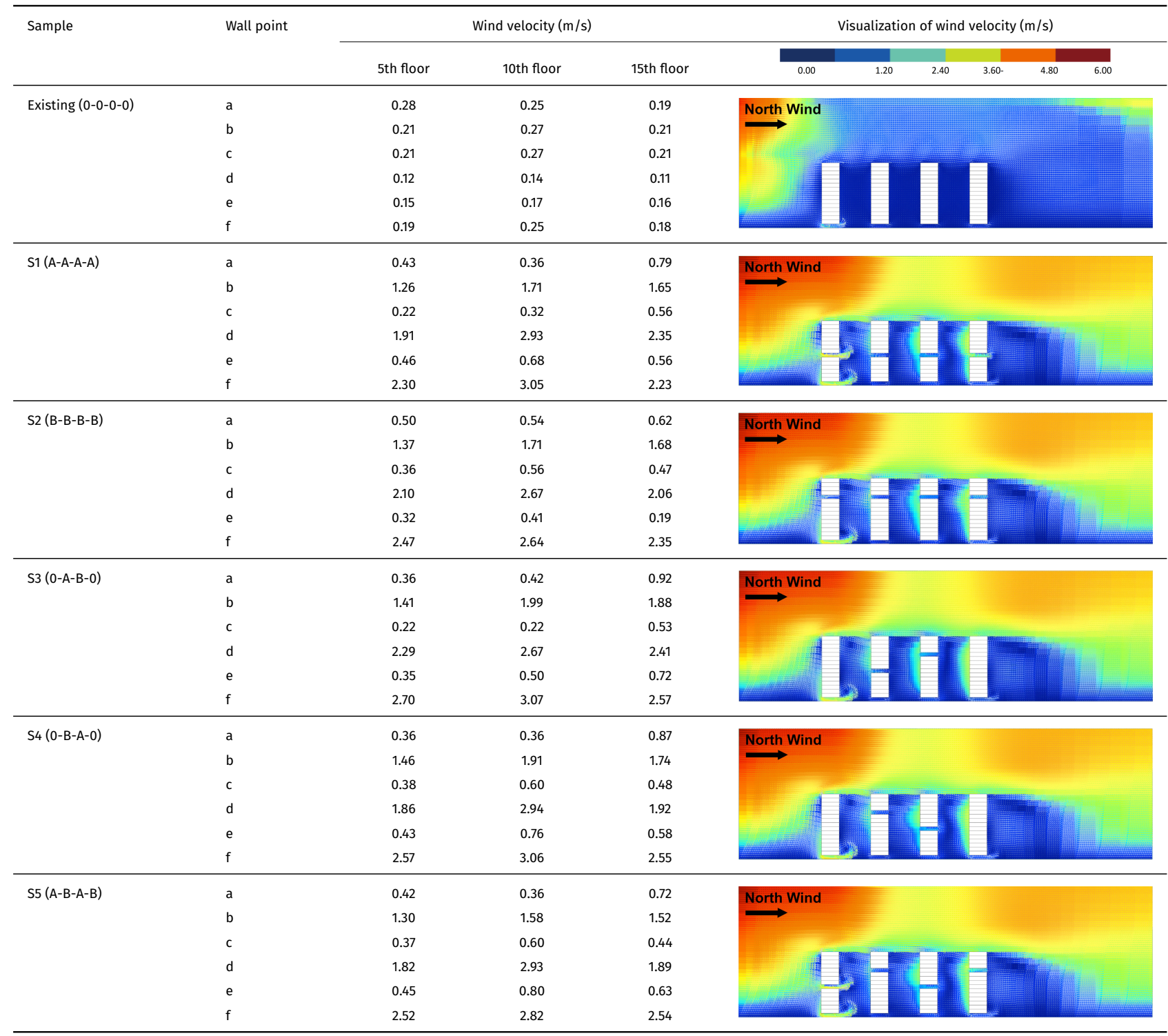




\subsection{Northwest wind}

In northwest wind simulations with a V speed of $2.68 \mathrm{~m} / \mathrm{s}$ (Table 2) tended to have the lowest WF at the point of the south wall $(\mathrm{a}, \mathrm{c}, \mathrm{e})$ on the 10th floor in areas 2 and 3 areas with an average V of $0.45 \mathrm{~m} / \mathrm{s}$. Meanwhile, the highest WF tended to be at the north wall point (b) on the 10th floor in area 2 with an average $\mathrm{V}$ of $3.76 \mathrm{~m} / \mathrm{s}$. Turbulence was in the high floor area (floors 13-15), on low levels (floors 1-5) in area 1 located between tower 1 and tower 2 , and on the north wall in each VD area in samples 1 to sample 5. WF was quite large in VD 1st floor (0) in tower 1 and 8th floor (A) and 12 (B) in each tower. The average difference in $V$ values was insignificant from existing simulations with some five sample simulations. Where the average $\mathrm{V}$ value of the existing and each sample was not very significant $(2.15 \mathrm{~m} / \mathrm{s}<$ $\mathrm{V}<2.23 \mathrm{~m} / \mathrm{s})$.

\section{DISCUSSION}

The selection of research sites in Jakarta represent climate conditions in Indonesia and even more so ASEAN, whose average climatic conditions are humid tropical. Research at a high-rise residential building in Jakarta gives an idea of the wind in high-rise affordable housing areas that desperately need optimal natural ventilation conditions.

In both simulated conditions with two different wind directions, there was a fairly similar pattern where the $\mathrm{WF}$ with the largest $\mathrm{V}$ was at point $\mathrm{d} 10$ (windward wall of tower 3 at 10th floor) with the turbulence that tended to be greater in the windward area (north wall) in each area. A significant difference in sample $1(\mathrm{~A}-\mathrm{A}-\mathrm{A}-\mathrm{A})$ north wind where WF again increased in the last tower (tower 4).

Based on the leeward and windward trendlines of the northwest wind (Figure 8), the five VD configuration samples in the rusun area had an average pattern of $\mathrm{V}$ value on windward which tended to be the same which was increased from wall $\mathrm{b}$ to wall $\mathrm{d}$ and experienced a slight decrease in wall $\mathrm{f}$ so that the highest $\mathrm{V}$ value was on wall $\mathrm{d}$.
Meanwhile, the leeward wall had a pattern of the $\mathrm{V}$ value that showed a decrease from wall a to wall e. In the diagonal wind direction, the VD configuration in the first tower building does not affect the distribution of wind significantly in the next tower buildings when viewed from the pattern of a sample of cases S1, S3, and S4. In this simulation, the configuration of rusun tower that became a research sample was more optimal with the condition of the direction of the wind diagonally (northwest) with more turbulence between the tower, a large WF on each VD 8th floor (A) and 12th floor (B) and a greater V value in the windward area (north wall).

Based on S1 of the north wind configuration alternative (Table 3), the reduction of the 8th floor, VD (A) in each tower except tower 4 with configuration (A-0-0-A), (0-A$0-\mathrm{A})$, and $(0-0-\mathrm{A}-\mathrm{A})$ had a WF similar to the windward area (north wall), and leeward (south wall) and VD (A) in tower 4 similar to the initial configuration (A-A-A-A). Meanwhile, the absence of VD (A) in towers 1 to 3, WF in VD (A) tower 4 decreases and WF conditions tended to be similar to existing WF conditions (0-0-0-0) where the small WF in windward areas and the small turbulence between each tower. The average difference in $\mathrm{V}$ values was quite significant from existing simulations with several five sample simulations. Where the average $\mathrm{V}$ value of the existing and each sample was not very significant with $2.15 \mathrm{~m} / \mathrm{s}<\mathrm{V}<2.23$ $\mathrm{m} / \mathrm{s}$. From the difference in the average value of $\mathrm{V}$ north wind above it can be known that the addition of VD other than the ground floor gives a significant influence on WF in the rusun area when the wind direction comes straight, especially from the north in this simulation. The difference between the average $\mathrm{V}$ value and the VD (A) sample added to two of the four-tower buildings was not very significant with the other $1.37 \mathrm{~m} / \mathrm{s}<\mathrm{V}<1.41 \mathrm{~m} / \mathrm{s}$. Meanwhile, the sample with VD (A) only in one of the four-tower buildings located in tower 4 had a significant difference in the average value of $\mathrm{V}$ when compared to one of the lowest average $\mathrm{V}$ values of one of the samples with a difference of $1.18 \mathrm{~m} / \mathrm{s}$.

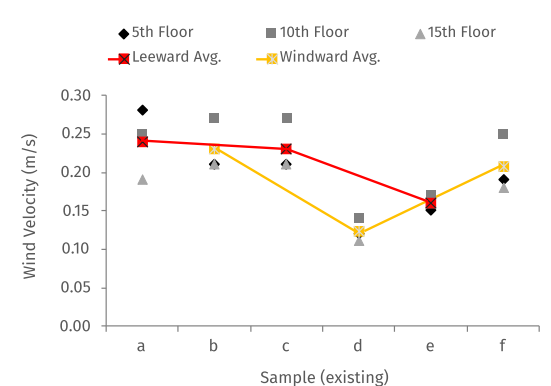

(a)

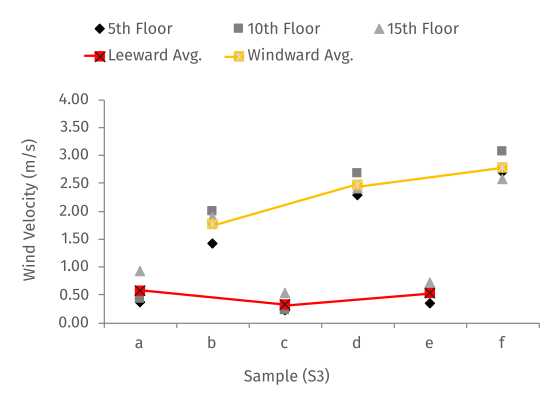

(d)

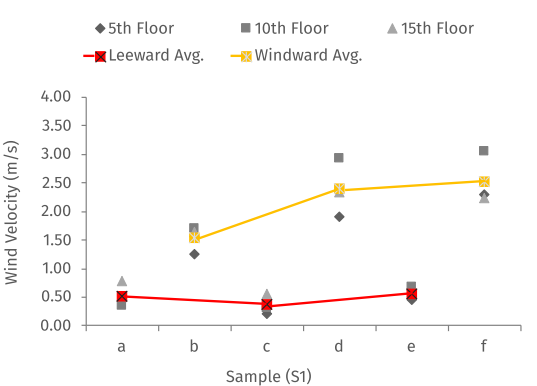

(b)

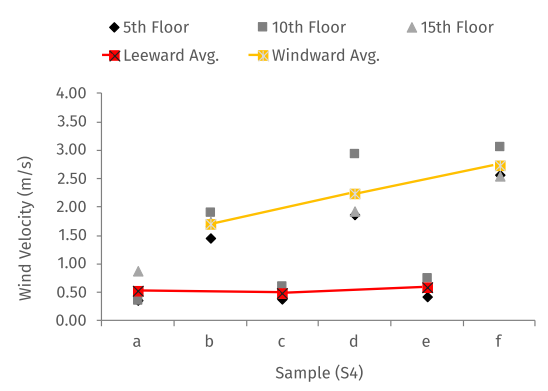

(e)

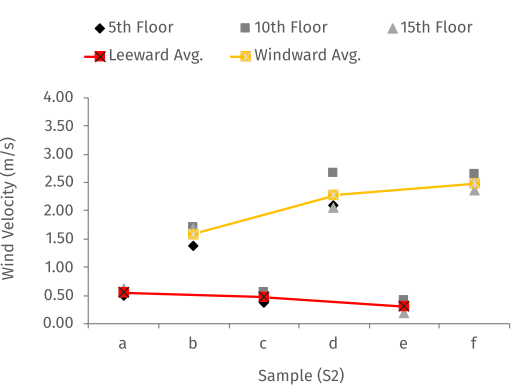

(c)

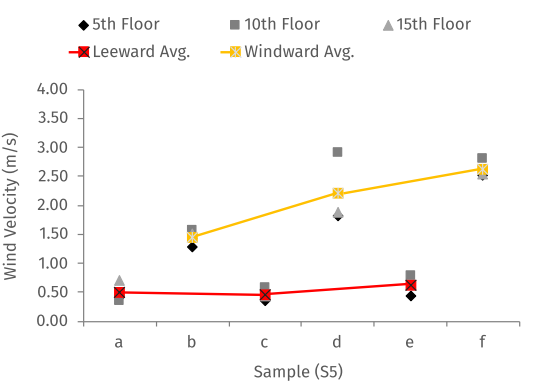

(f)

FIGURE 7. Leeward and windward trendlines of north wind. (a) Existing configuration (0-0-0-0), (b) S1 (A-A-A-A), (c) S2 (B-B-B-B), (d) S3 (0-A-B-0), (e) S4 (0-B-A-0), (f) S5 (A-B-A-B). 
In general, when compared to previous research $(\mathrm{Ng}$ 2009), with the composition of urban canyons $\mathrm{W}: \mathrm{H}=1: 2$, there was a difference in wind turbulence between towers when added VD in tower buildings. WF that comes from the basic VD of the building, the middle of the building, and from the top of the building has the possibility of creating a more diverse air vortex between the building towers. Although it had a V pattern on windward and leeward that was almost similar, it had an air vortex pattern that varies depending on the composition of each VD.

\section{CONCLUSIONS}

It is expected that research with a sample of high-rise affordable housing in the city of Jakarta, Indonesia will be a reference for residential property developers, especially in the scope of countries in ASEAN that have similar climates. Furthermore, this research can be a reference for the government and private sector in conducting literature studies in terms of natural ventilation of high-rise affordable housing areas at the planning and preparation stage.

After researching with the simulation method using the Butterfly software to run CFD simulation. With the geometry of tower buildings in the Rusun Rorotan area with slab blocks arranged as many as four tower units from north to south with a tower height of $51.2 \mathrm{~m}$ and a distance between towers of $25 \mathrm{~m}$, the addition of VD variations at a certain floor height (8th and 12th floor) revealed several findings.

First, the object of urban ventilation research that focuses on the permeability of buildings with the Rusun Rorotan area as a geometry case study shows that the addition of VD in some upper floors has a significant influence on wind distribution among tower buildings.

Second, in CFD simulation results with test points on certain floors (5th, 10th, and 15th floor) in windward (south wall) and leeward (north wall) positions with a total of 18 test points with wind conditions from the north of the region or winds with perpendicular directions have significant differences from WF and V values. Where the average value of the existing $\mathrm{V}$ is far below the average value of the fifth V sample rusun with $0.20 \mathrm{~m} / \mathrm{s}$ versus $1.28 \mathrm{~m} / \mathrm{s}$ in sample 2 which has the lowest average $V$ value of the five samples. Meanwhile, in wind conditions that come diagonally from the northwest to the rusun area there is no significant difference in the average $V$ value between existing conditions and the five samples.

And third, from the simulation results from both directions of wind coming both perpendicular (north) and diago-

TABLE 2. Northwest wind simulation results.

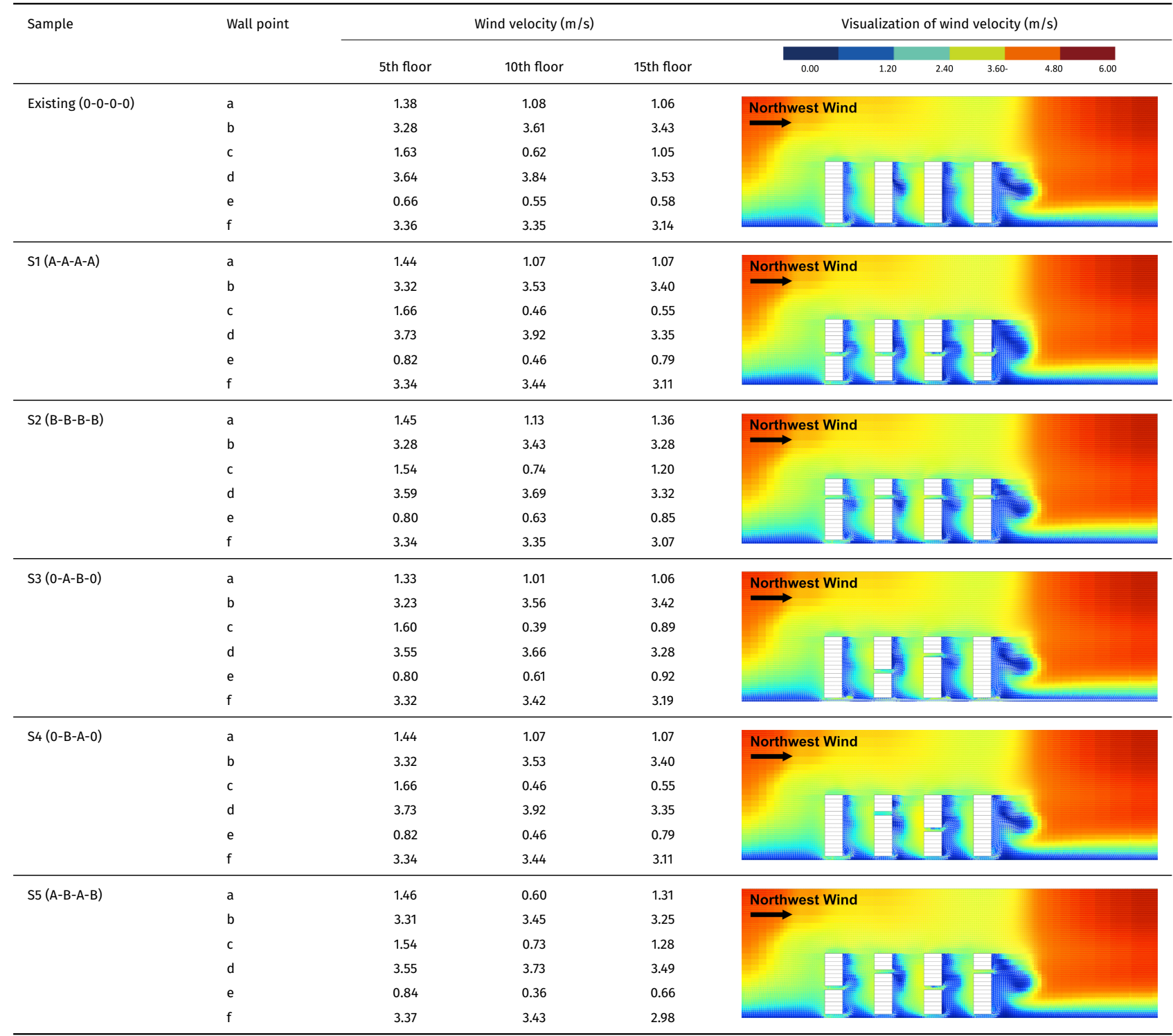


nal (northwest), V values tended to be high in the windward area (north wall) and high on the 10th floor.

From the results of this study, windward walls in each tower building are more optimal in obtaining wind distribution in the rusun unit from the direction of the wind coming perpendicular or diagonal. So based on these circumstances, the rusun unit located in the windward wall area will be more optimal in receiving wind distribution depending on where the wind comes from to the rusun area. The placement of VD on the middle and upper floors of the first tower building did not have a significant influence on the distribution of wind to the next tower building. Therefore, the addition of VD in the first tower building is not very necessary if you want to increase the wind distribution in the rusun area. This research focusing on wind speed criteria can be one of the variables to find a thermal comfort scale with a specific temperature and radiation value. From the optimal WF and V, the natural air conditioning in the rusun unit can be achieved to reduce the use of artificial air conditioning that can reduce the energy consumption of artifi-

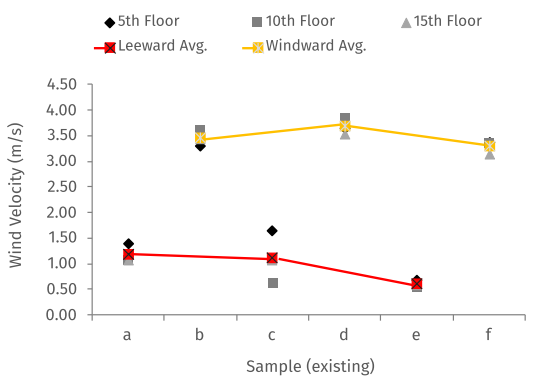

(a)

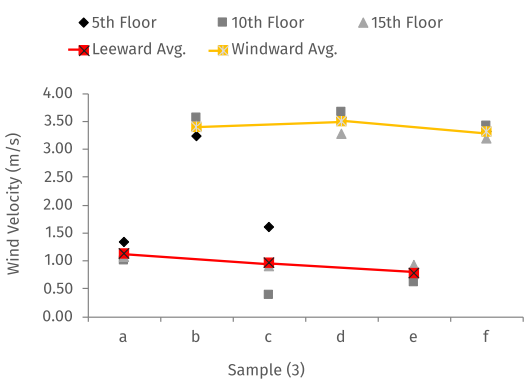

(d)

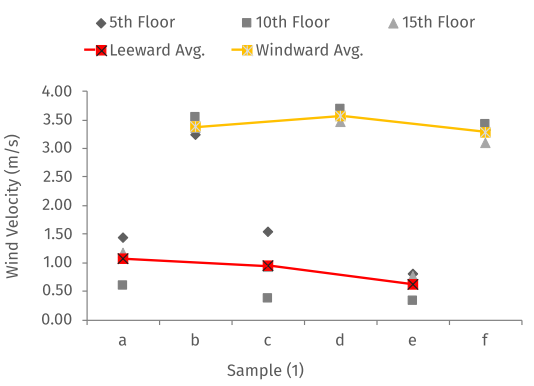

(b)

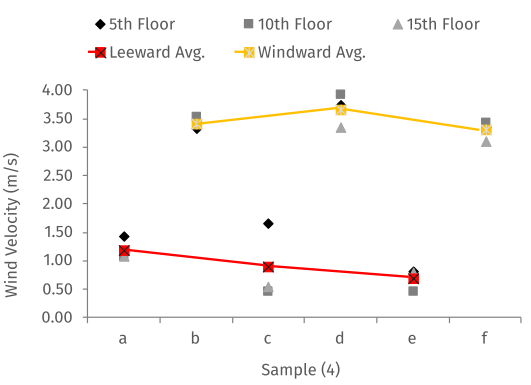

(e)

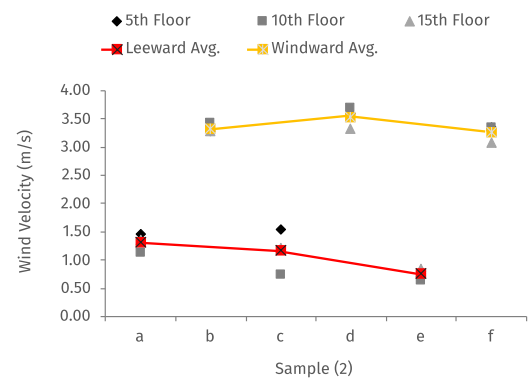

(c)

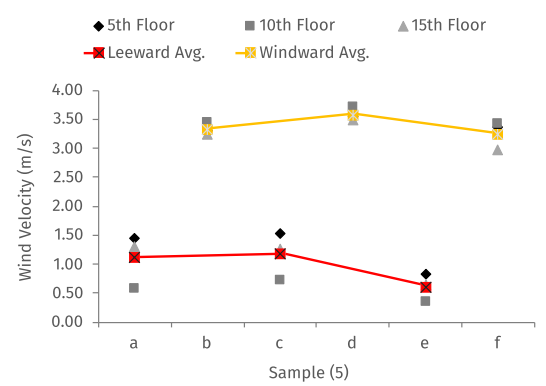

(f)

FIGURE 8. Leeward and windward trendlines of northwest wind. (a) Existing configuration (0-0-0-0), (b) S1 (A-A-A-A), (c) S2 (B-B-B-B), (d) S3 (0-A-B-0), (e) S4 (0-B-A-0), (f) S5 (A-B-A-B).

TABLE 3. North wind configuration alternative.

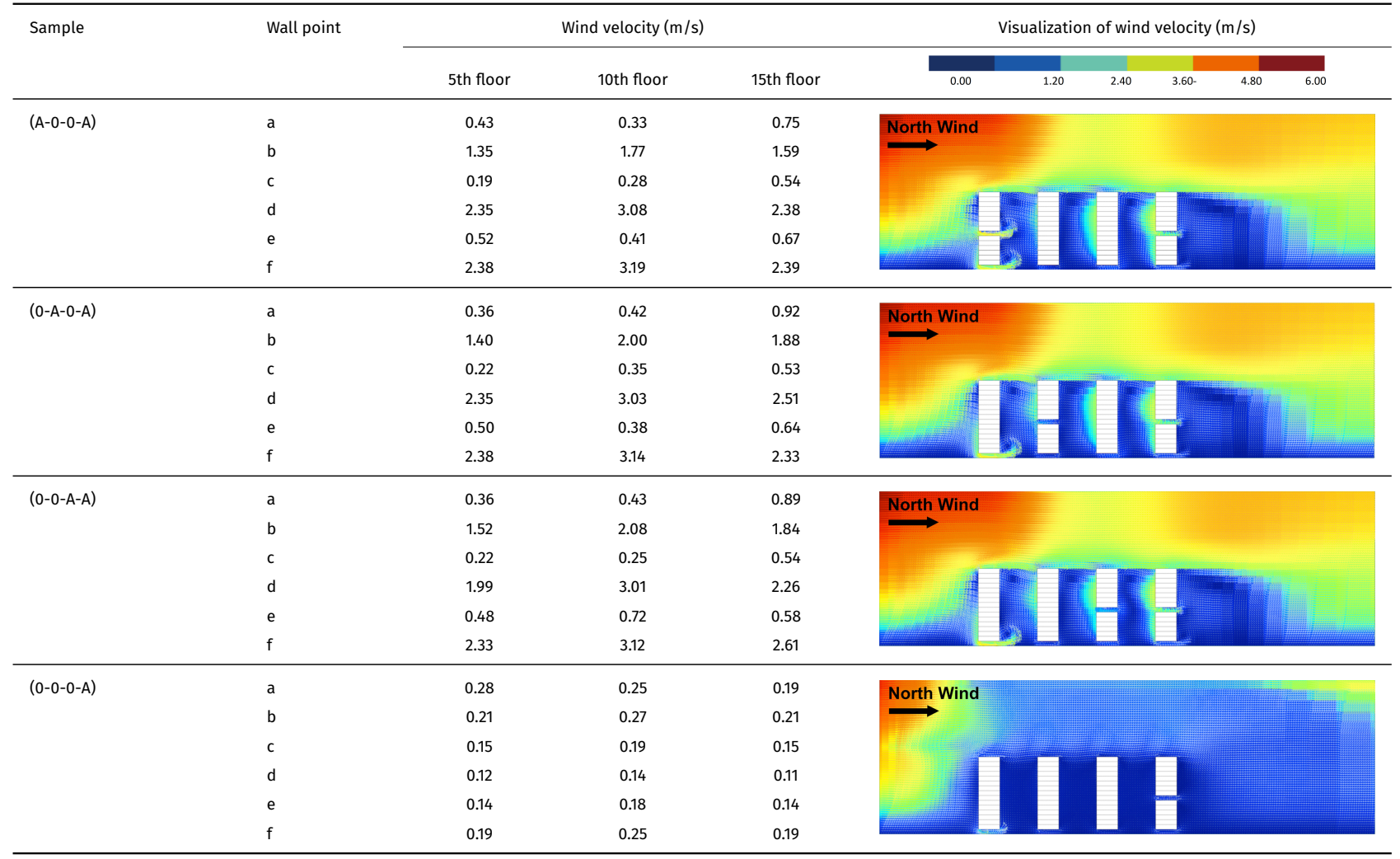


cial air conditioning which is one of the criteria to achieve a sustainable rusun area.

It takes more in-depth validation to assign a $\mathrm{V}$ value to the rusun area, such as direct calculations in the field using proper equipment. But at the simulation stage can provide an overview for the existing evaluation process as well as in the development stage in further transformation of the shape and geometry of the building. For the future stage of development, simulations such as those conducted in this study can be a reference in getting an overview of regional wind conditions from the shape and geometry of building design to existing wind conditions.

\section{ACKNOWLEDGMENTS}

We as authors show this research to academy actors and practitioners in the field of architectural technology and settlements to be a trigger for science and research in the future. The authors dedicate this research to open access. The authors also thank the Department of Architecture and Planning of Unversitas Gadjah Mada, Yogyakarta, Indonesia, which became the place for the author's research institute.

\section{AUTHORS' CONTRIBUTIONS}

MAR conceived of and carried out the study, and wrote and edited the manuscript. NIM directed the study and provided proofreading and editing of the manuscript. Both authors read and approved the final version of the manuscript.

\section{COMPETING INTERESTS}

We declare there is no conflict between authors in the preparation of manuscripts from the beginning of ideas, writing, and the final stage of manuscript preparation.

\section{REFERENCES}

Adabre MA, Chan APC, Darko A, Osei-Kyei R, Abidoye R, Adjei-Kumi T. 2020. Critical barriers to sustainability attainment in affordable housing: international construction professionals' perspective. J Cleaner Prod. 253:119995. doi:10.1016/j.jclepro.2020.119995.

Cairns S, Jacobs JM, Yingying J, Padawangi R, Siddique S, Tan E. 2014. Singapore's void decks. In: Lim WSW, editor. Public space in urban Asia. Singapore: World Scientific Publishing. p. 80-89. doi:10.1142/9033.

DeKay M, Brown GZ. 2014. Sun, wind, and light: architectural design strategies. Hoboken: John Wiley \& Sons.

Franke J. 2007. Best practice guideline for the CFD simulation of flows in the urban environment. Brussels: COST Office.

Givoni B. 1998. Climate considerations in building and urban design. New York: John Wiley \& Sons.

Katili AR, Boukhanouf R, Wilson R. 2015. Space cooling in buildings in hot and humid climates - a review of the effect of humidity on the applicability of existing cooling techniques. Paper presented at: SET 2015. Proceedings of 14th International Conference on Sustainable Energy Technologies; Nottingham, United Kingdom. doi:10.13140/RG.2.1.3011.5287.

Keung J. 2010. Building planning and massing (green building platinum series). Singapore: Building and Construction Authority.
Lee J, Lee KS, Lim J. 2015. Passive design techniques applied to green buildings as an aesthetic and spatial design concept. J Green Build. 10(2):79-109. doi:10.3992/ jgb.10.2.79.

Ng E. 2009. Designing high-density cities: for social and environmental sustainability. London: Routledge. doi: 10.4324/9781849774444.

Peel MC, Finlayson BL, McMahon TA. 2007. Updated world map of the Köppen-Geiger climate classification. Hydrol Earth Syst Sci. 11(5):1633-1644. doi:10.5194/hess-1 1-1633-2007.

Satwiko P. 2004. Fisika bangunan [Building physics]. Yogyakarta: Penerbit ANDI.

Sugini D. 2014. Kenyamanan termal ruang [Room thermal comfort]. Yogyakarta: Graha Ilmu.

Vialita E, Rahmawati D. 2020. How Liveable is living in public housing? A liveability measurement at lowincome apartment of Kompleks Rumah Susun Sombo, Surabaya. IOP Conf Ser: Earth Enviro Sci. 452(1):012129. doi:10.1088/1755-1315/452/1/012129. 